\title{
Reflexões sobre Casos de Ensino Memoráveis
}

\author{
Reflections on Memorable Teaching Cases
}

Paula Castro Pires de Souza Chimenti ${ }^{1,2}$

No $79^{\circ}$ Academy of Management Conference, tive a oportunidade de assistir a uma palestra de Andrew Van de Ven, que foi o keynote speaker da Teaching and Learning Conference. Como se já não bastasse a minha emoção ao ver de perto um acadêmico que admiro profundamente, ainda fui surpreendida com sua declaração inicial, que me levou lágrimas aos olhos. O que ele disse foi mais ou menos isso, em uma tradução livre: "Estou muito feliz em falar para vocês na Teaching e Learning Conference porque, afinal de contas, o que nós somos? Nós somos professores! Nós somos professores! Antes de tudo, somos professores!".

Curioso como uma afirmação tão óbvia pôde me comover, mas as lágrimas têm uma explicação. Nos tempos atuais, com tantas pressões e tantos chapéus para usarmos, às vezes podemos acabar nos esquecendo da nossa vocação.

Acho que este foi o principal motivo que me fez aceitar o convite do Prof. Wesley Mendes para assumir a editoria de casos para ensino da RAC. Os casos são talvez o lugar onde o professor e o pesquisador se encontram com mais sinergia. São, essencialmente, ferramentas de ensino criadas para a sala de aula. Porém, para criar um bom caso para ensino, há que se exercitar a verve de pesquisador: investigar, refletir e escrever.

\footnotetext{
' Universidade Federal do Rio de Janeiro, Instituto de Pós-Graduação e Pesquisa em Administração (COPPEAD), Rio de Janeiro, RJ, Brasil.

${ }^{2}$ Editora Associada de Casos para Ensino da RAC - Revista de Administração Contemporânea.
}

Outro dia um aluno comentou: "Professora, a aula terminou, mas eu fiquei refletindo sobre o caso que discutimos a semana inteira". Este é um daqueles momentos em que penso que estou fazendo meu trabalho direito. Felizmente, não é incomum reencontrar ex-alunos do mestrado ou do MBA Executivo anos depois e vê-los falar sobre protagonistas de casos de ensino memoráveis que os acompanham e inspiram em suas vidas profissionais.

$\mathrm{Eu}$, por exemplo, jamais me esquecerei de James Burke, CEO da Johnson \& Johnson que teve de lidar com o envenenamento de Tylenol que matou seis pessoas nos EUA no início dos anos 80 (Tedlow \& Smith, 2005). Ou de Strauss Zellnick, CEO da BMG nos anos 90 , que sentiu na pele a disrupção da indústria da música causada pela digitalização (Rivkin \& Meier, 2005). Isto por dois motivos: porque assisti aulas ministradas por professores maravilhosos (Rohit Deshpande e Roberto Nogueira) e porque são casos de ensino simplesmente incríveis.

De fato, todos nós nos lembramos de algum 'eureka moment', quando descobrimos alguma coisa que não sabíamos antes. São momentos deliciosos e inesquecíveis. Os bons casos de ensino são capazes de provocar estes momentos que nos inspiram e acompanham pela vida. Mas como provocar isso?

Como citar: Chimenti, P. C. P. de S. (2020). Reflections on memorable teaching cases. Revista de Administração Contemporânea, 24(5), 376-379. https://doi.org/10.1590/1982-7849rac2020200102 
É necessário engenho e criatividade. A arte que distingue um texto comum de um inspirado. Nos casos de ensino, estas habilidades precisam aparecer tanto no caso, que apresenta protagonistas e dilema, quanto nas notas de ensino, que auxiliam o professor no desenho de uma aula memorável.

Os elementos destacados a seguir não compõem uma lista definitiva ou exaustiva. São antes o resultado de reflexões que tenho feito a partir dos inúmeros casos de ensino que li e utilizei em minha vida profissional, bem como de diversos tutoriais e cursos que fiz sobre a escrita e utilização de casos de ensino, dentre os quais destaco e recomendo o Global Colloquium on ParticipantCentered Learning, da Harvard Business School. É também uma tentativa de resposta aos colegas que, desde que assumi a editoria de casos para ensino da RAC, tantas vezes me questionaram: "Mas, afinal, o que faz um bom caso para ensino?".

Antes de prosseguir, é importante destacar dois aspectos deste editorial:

O primeiro é que não se trata de um documento que ensine a escrever casos, para isso há ótimas referências listadas ao final deste texto. Roberts (2012) oferece um passo -a-passo preciso para escrever casos, assim como Leenders, MauffetteLeenders e Erskine (2001). Especificamente no Brasil, Alberton e Silva (2018), Faria e Figueiredo (2013) e Roesch (2007) oferecem um excelente panorama sobre como produzir bons casos de ensino.

Ao invés de focar no processo, que pode ser muito diferente dependendo das circunstâncias e experiência de quem vai escrever o caso, trato aqui do caso como produto final, enfatizando os elementos que esperamos de um bom caso de ensino.

O segundo aspecto é que, apesar de existirem diferentes tipos de casos de ensino, esta nota trata de casos-problema baseados em pesquisa empírica sobre organizações ou indivíduos (Roberts, 2012), por acreditar que compõem a maioria dos casos propícios para publicação em veículos como a RAC. Assim, não estou tratando de casos-demonstração (Roesch, 2007), ou tampouco de casos criados a partir da experiência geral do pesquisador, ou baseados em dados secundários.

\section{O CASO}

Casos de ensino são, antes de tudo, instrumentos de aprendizado (Roberts, 2012). Assim, é fundamental que o autor tenha em mente o que quer ensinar com aquele caso, antes mesmo de começar a redigi-lo. Um bom caso atinge seus objetivos de aprendizado a partir de uma boa história e das análises que os alunos farão a partir da sua leitura. Tendo isto em mente, destaco alguns elementos fundamentais:

- Dilema: um caso memorável tem um dilema impactante, cuja solução está longe de ser óbvia. O professor Noam Wasserman, um especialista na escrita de casos da HBS, uma vez me disse durante um seminário que nada supera a realidade. Estávamos na ocasião comentando um caso que ele escreveu que começa com o protagonista acordando em pânico no meio da madrugada (Wasserman \& Maurice, 2012). Não era uma situação inventada, era real.

Um dos primeiros passos para escrever um bom caso para ensino é uma boa notícia para nós professores-pesquisadores: descubra o dilema. Entreviste os protagonistas, conheça profundamente a história da organização. O dilema não deve ser inventado, deve emergir da sua pesquisa sobre o caso.

- Protagonista: todo caso memorável tem um protagonista memorável. Idealmente, trata-se de uma pessoa real que viveu aquele dilema e foi o tomador de decisão. Mesmo que se decida mudar o nome para proteger a fonte, lembre sempre que a realidade é melhor que a ficção. O protagonista é aquele personagem com o qual os alunos precisam se identificar, é o dono da camisa que eles irão vestir. Quanto mais instigante, melhor a discussão.

- Dados: não basta contar a história, é preciso apresentar elementos para o aluno desenvolver sua própria análise e chegar às suas conclusões. Neste sentido, os dados precisam trazer informações que permitam a análise aprofundada e levem a uma discussão rica em sala de aula. Portanto, o trabalho investigativo dos autores é fundamental, buscando informações que devem ir além do lugar-comum e do domínio público.

Assim, apesar de todo caso ser uma simplificação da realidade, os dados apresentados não devem ser óbvios ou induzir a solução. Muitas vezes os gestores se veem em dúvida sobre qual caminho seguir justamente porque a realidade é complexa e caótica. Os dados apresentados devem replicar na medida do possível a realidade, por vezes trazendo elementos que não seriam necessários à tomada de decisão. Lembre-se que, em casos de ensino, vale a máxima que ouvi da professora Jannice Hammond (citando Rob Freund, do MIT): "Em casos de ensino, não importa o que você cobre, mas o que se descobre" ("It's not what you cover, it's what you uncover"). 


\section{AS NOTAS DE ENSINO}

Quanto melhores as notas de ensino, melhor a aula que aquele caso vai gerar. A nota de ensino é o local da generosidade do autor, quando ele compartilha todo seu conhecimento com outros instrutores que utilizarão o caso. Para o marinheiro de primeira viagem, as notas oferecem um porto seguro.

O fio condutor de uma boa nota de ensino é o takeaway, ou seja, quando aquela aula terminar, o que queremos que o aluno leve com ele. Cada aula é organizada a partir de um takeaway, que deve ser surpreendente e importante.

Austin (1993) oferece um ótimo guia para a redação das notas de ensino. Para o autor, elas devem conter 5 elementos principais:

- Sinopse: sobre o que é o caso;

- Posicionamento: onde o caso se situa;

- Objetivos de aprendizado: por que utilizamos este caso;

- Análise: o que vamos ensinar com este caso;

- Processo de ensino: como vamos ensinar.

Além destes elementos, gostaria de destacar dois outros:

- Pastures: são os grandes blocos de discussão de um caso. As boas notas de ensino oferecem um guia de pastures, formando um mapa geral de como a discussão do caso deve evoluir. Esta abordagem é muito interessante pois permite que a discussão dentro de cada pasture corra mais fluida e solta, enquanto o professor mantém o controle da aula a partir do mapa geral de todos os pastures e sua sequência.
- Twist, ou virada: esta é uma opinião pessoal, que aprendi com grandes mestres de sala de aula como Kleber Figueiredo e Victor Almeida: casos memoráveis têm viradas. Os melhores 'eureka moments' ocorrem quando os alunos são surpreendidos com uma virada inesperada da análise, que parecia ir por um caminho, mas acaba revelando outro. É muito difícil escrever casos assim, então este não é um elemento fundamental, mas é a 'cereja do bolo' quando acontece. É também um momento em que a discussão de casos se aproxima mais da realidade, pois quantas vezes a vida já não nos surpreendeu?

\section{VAMOS ESCREVER CASOS DE ENSINO MEMORÁVEIS?}

Termino este editorial com um convite para vocês. Abrimos uma chamada para casos de ensino que abordem os desafios nos negócios gerados pelo Covid-19 (Chimenti \& Marques, 2020). Esta chamada especial para artigos da RAC busca promover a aprendizagem em um momento tão difícil. A ideia é criar casos de ensino que desenvolvam aprendizado e discussão em sala de aula sobre como o mundo e as empresas podem reagir às profundas mudanças que estamos experimentando. Eu e o editor convidado, Prof. Leonardo Marques, estamos aguardando seus trabalhos.

Um abraço, se cuidem e até breve!

\section{REFERÊNCIAS}

Austin, J. (1993). Teaching notes: Communicating the teacher's wisdom [Folheto $\mathrm{N}^{\circ}$ 5]. Harvard Business School Publishing Division, Boston, MA, USA. Retrieved from https://www.hbs.edu/faculty/Pages/item. aspx?num=23299

Alberton, A., \& Silva, A. (2018). Como escrever um bom caso para ensino? Reflexões sobre o método. Revista de Administração Contemporânea, 22(5), 745-761. https:// doi.org/10.1590/1982-7849rac2018180212

Chimenti, P., \& Marques, L. (2020, April). Teaching covid-19's impact on business. Zenodo. http://doi.org/10.5281/ zenodo. 3744800

Erskine, J. A., Leenders, M. R., \& Mauffette-Leenders, L.A. (1998). Teaching with cases. London, Ontario, Canada: Richard Ivey School of Business.
Faria, M., \& Figueiredo, K. (2013). Casos de ensino no Brasil: Análise bibliométrica e orientações para autores. Revista de Administração Contemporânea, 17(2), 176-197. https://doi.org/10.1590/S1415-65552013000200004

Leenders, M. R., Mauffette-Leenders, L. A., \& Erskine, J. A. (2001). Writing cases (4th ed.). London, Ontario, Canada: Richard Ivey School of Business.

Rivkin, J. W., \& Meier, G. (2000, July 3). BMG entertainment. Harvard Business School, Case 9-701-003. Retrieved from https://www.hbs.edu/faculty/Pages/item. aspx?num $=27305$

Roberts, M. (2012). Developing a teaching case (Abridged). Harvard Business School, Background Note, 9-901-055. Retrieved from https://www.hbs.edu/faculty/Pages/ item.aspx?num=28256 
Roesch, S. M. A. (2007). Notas sobre a construção de casos para ensino. Revista de Administração Contemporânea, $11(2)$, 213-234. https://doi.org/10.1590/S141565552007000200012

Tedlow, R., \& Smith, W. (2005). James Burke: A career in American business (A). Harvard Business School, Case 9-389-177. Retrieved from https://www.hbs.edu/faculty/Pages/ item.aspx?num $=11501$

Wasserman, N., \& Maurice, L. (2012). Savage beast (A). Harvard Business School, Case 9-809-060. Retrieved from https://www.hbs.edu/faculty/Pages/item. aspx?num $=36725$

\section{Autoria}

\section{Paula Castro Pires de Souza Chimenti*}

Rua Pascoal Lemme, $n^{\circ}$ 355, Ilha do Fundão, 21941-901, Rio de Janeiro, RJ, Brasil.

E-mail: paula.chimenti@coppead.ufrj.br

๑ https://orcid.org/0000-0002-6492-4072

* Autor Correspondente

\section{Conflito de Interesses}

A autora informou que não há conflito de interesses.

\section{Direitos Autorais}

A RAC detém os direitos autorais deste conteúdo.

\section{CORPO EDITORIAL CIENTÍFICO E EQUIPE EDITORIAL PARA ESTA EDIÇÃO:}

\section{Conselho Editorial}

Anielson Barbosa da Silva (UFPB, João Pessoa, Brasil) Antonio Carlos Gastaud Maçada (UFRGS, Porto Alegre, Brasil) Ely Laureano Paiva (FGV, São Paulo, Brasil)

Fabio Vizeu Ferreira (UP, Curitiba, Brasil)

Maria José Tonelli (FGV, São Paulo, Brasil)

Rogério Hermida Quintella (NPGA/UFBA, Salvador, Brasil)

Valmir Emil Hoffmann (UnB, Brasília, Brasil)

Wesley Mendes-da-Silva (EAESP/FGV, São Paulo, Brasil)

Editor-chefe

Wesley Mendes-da-Silva (EAESP/FGV, São Paulo, Brasil)

\section{Editores Associados}

André Luiz Maranhão de Souza-Leão (UFPE, Recife, Brasil)

Fabio Caldieraro (EAESP/FGV, São Paulo, Brasil)

Gilnei Luiz de Moura (UFSM, Santa Maria, Brasil)

Henrique Castro Martins (IAG PUC-Rio, Rio de Janeiro, Brasil)

Ismael Ali Ali (Kent State University, Ohio, EUA)

Marcus Cunha Junior (University of Georgia, EUA)

Paula Castro Pires de Souza Chimenti (UFRJ/Coppead, Rio de Janeiro, Brasil)

Paulo César Matui (UniGranRio, Rio de Janeiro, Brasil)

Samy Dana (FGV/EAESP, São Paulo, Brasil)

\section{BIBLIOGRAFIA RECOMENDADA}

Corey, E. R. (1999). Writing cases and teaching notes [Folheto $\mathrm{n}^{\circ}$ 9-399-077]. Harvard Business School Publishing Division, Boston, MA, USA.

Yue, T. (2016). How to write a good teaching note. Rotterdam, Netherlands: Rotterdam School of Management, Erasmus University.

Roesch, S. M. A., \& Fernandes, F. (2007). Como escrever casos para o ensino de administração. São Paulo: Atlas.

\section{Corpo Editorial Científico}

Aureliano Angel Bressan (CEPEAD/UFMG, Belo Horizonte, Brasil) Bryan Husted (York University, Canadá)

Carlos M. Rodriguez (Delaware State University, EUA)

Cristiana Cerqueira Leal (Universidade do Minho, Portugal)

Diógenes de Souza Bido (Mackenzie, São Paulo, Brasil)

Elin Merethe Oftedal (University of Tromsø, Noruega) Emilio Jose Monteiro Arruda Filho (Unama, Belém, Brasil) Fábio Frezatti (FEA/USP, São Paulo, Brasil)

Felipe Monteiro (Wharton/University of Pennsylvania, EUA)

Howard J. Rush (University of Brighton, Reino Unido)

James Robert Moon Junior (Georgia Institute of Technology, EUA) John L. Campbell (University of Georgia, EUA)

José Antônio Puppim de Oliveira (United Nations University, Yokohama, Japão)

Julián Cárdenas (Freie Universität, Berlin, Alemanha)

Lucas Barros (EAESP/FGV, São Paulo, Brasil)

Luciano Rossoni (UniGranRio, Rio de Janeiro, Brasil)

M. Philippe Protin (Université Grenoble Alpes, França)

Paulo Estevão Cruvinel (Embrapa Instrumentação, São Carlos, Brasil)

Rodrigo Bandeira de Mello (Merrimack College, EUA)

Rodrigo Verdi (MIT Massachusetts Institute of Technology, Cambridge, EUA)

Valter Afonso Vieira, (UEM, Maringá, Brasil)

Wagner Kamakura (Jones Graduate School of Business, Rice University, Houston, EUA)

\section{Editoração}

Diagramação e normas da APA: Kler Godoy (ANPAD, Maringá, Brasil)

Periodicidade: Bimestral.

Circulação: Acesso totalmente gratuito.

Indexadores e Diretórios

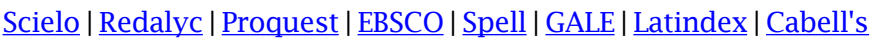
| Capes/Qualis | Ulrich's | DOAJ | Clase | DIADORIM | ERIHPlus 